\title{
Splenic Injury and ERCP: A Possible Risk for Patients with Advanced Chronic Pancreatitis
}

\author{
Ryan R. Gaffney $^{\mathrm{a}}$ Vishal Jain ${ }^{\mathrm{b}}$ Matthew T. Moyer \\ ${ }^{a}$ Department of Internal Medicine and ${ }^{b}$ Division of Gastroenterology/ \\ Hepatology, Penn State Hershey Medical Center, Hershey, Pa., USA
}

\section{Key Words}

Endoscopic retrograde cholangiopancreatography · Splenic injury · Hematoma . Chronic pancreatitis

\begin{abstract}
Splenic injury is a rare but potentially life-threatening complication of endoscopy, with very few cases of endoscopic retrograde cholangiopancreatography (ERCP)-induced injury reported in the literature. Here we report a patient with chronic alcoholic pancreatitis who was diagnosed with a sub-capsular splenic laceration nearly 6 days after an ERCP. Clinicians should be alerted to the potential post-procedure complications associated with ERCP, particularly as this procedure is being utilized more frequently for the management of patients with complex hepatobiliary and pancreatic conditions.
\end{abstract}

\section{Introduction}

With the increased use of endoscopic retrograde cholangiopancreatography (ERCP) for patients with pancreatico-biliary disease, a subset of specific procedural risk factors has been established, including pancreatitis, perforation, hemorrhage, and infection [1]. The procedure itself carries a complication rate between 5 and $10 \%$ [2], but some of the rarer complications are not usually considered in the immediate post-procedure time frame. An uncommon but potentially life-threatening complication is splenic laceration, for which there are few reported cases and even less predictors of occurrence. Here we present a patient with chronic alcoholic pancreatitis who was diagnosed with a splenic laceration after undergoing ERCP and suggest that chronic pancreatitis should be considered a risk factor for this potentially fatal complication. 


\section{Case Report}

A 48-year-old male with a history of chronic pancreatitis and multiple previous ERCPs for stenting of a persistent common bile duct stricture underwent an additional ERCP for a stent exchange. His last ERCP was approximately 3 months prior at which time a biliary duct stent was removed and a pancreatic duct stent as successfully replaced. Unfortunately the patient's symptoms of chronic abdominal pain persisted despite these interventions, and he was referred for an additional ERCP. During this procedure, ampullary cannulation was performed without difficulty, and cholangiography revealed a chronic, tight distal common bile duct stricture with dilation of the common hepatic duct. No stones were detected after multiple balloon sweeps, and a replacement biliary duct stent was deployed because of inadequate drainage. A prominent stricture in the head region of the pancreas was detected and unchanged compared to the previous ERCP, and the previously placed pancreatic duct stent was removed without incident. The total procedure time was approximately 45 minutes. There were no unplanned events during the ERCP and the patient was sent home post-procedure without any noted complaint.

Six days later, he presented to an outside facility with progressive, localized left upper quadrant abdominal pain, and was admitted after axial computed tomography (CT) of the abdomen and pelvis revealed a splenic laceration with associated sub-capsular hematoma (fig. 1 ). The patient denied recent trauma and was subsequently transferred to our facility, where admission laboratory data revealed a hemoglobin of $9.7 \mathrm{~g} / \mathrm{dl}$, a nearly 2-gram decline post-ERCP. Liver function tests, lipase and amylase levels, and coagulation markers were normal. Vital signs did not reveal tachycardia or hypotension. Physical exam demonstrated vague tenderness along the left upper quadrant with radiation to the left shoulder. He was managed conservatively after surgical consultation with serial abdominal exams, interval ultrasounds and pain control, and was discharged in good condition after 5 days. Follow-up CT imaging 1 month post-discharge revealed progressive resolution of the splenic hematoma.

\section{Discussion}

Splenic injury is a rare but known complication of endoscopy, reported most commonly after colonoscopy. Predisposing factors include a decrease in mobility between the spleen and surrounding organs, excess traction on the splenocolic and gastrosplenic ligaments, and direct trauma to the spleen [3]. Since the first described post-ERCP case in a patient with gallstone pancreatitis [4], only 11 total cases of splenic injury have been reported in the timeframe post-ERCP [4-14]. Several pathologic findings of the spleen have been categorized, including laceration [5], sub-capsular hematoma [6], short gastric vessel avulsion [7], and direct tearing of the splenic capsule [8].

In our review of the literature, the only recurrent, associated variable for ERCP-induced splenic injury is chronic pancreatitis [8-11], as was the case in this patient. The mechanism of injury is possibly related to the intimate relationship between the splenic hilum and pancreatic tail, which ultimately permits direct inflammatory spread into the spleen. In fact, spontaneous splenic parenchymal complications ranging from subcapsular hematoma to complete organ rupture are being increasingly reported as sequelae of acute and chronic pancreatitis [15]. In our case, chronic calcific pancreatitis related to alcohol consumption was evident by extensive pancreatic calcifications and a significantly dilated common bile duct visualized on imaging studies (fig. 2). This patient's chronic pancreatitis had unfortunately progressed both clinically and radiographically over a period of several months despite multiple ERCPs and stenting of biliary and pancreatic ductal strictures. It is entirely plausible that the resulting calcification and fibrosis between the 
supporting ligaments of the stomach, pancreas, and spleen may then lead to excessive mechanical tension and potential for intra-procedural splenic injury when significant scope pressure is introduced, as can occur with gastric bowing of the scope during ERCP. This increases the risk of traction injury to the spleen during endoscope manipulation in the stomach, ultimately causing splenic tearing or vascular avulsion.

This case emphasizes the need for awareness of splenic injury in patients with persistent post-ERCP left upper quadrant abdominal pain, particularly when seen in conjunction with hemodynamic instability or acute anemia developing within the timeframe post-procedure. Whereas other reports showed a lag time of up to $72 \mathrm{~h}$ after endoscopy [12], our case is unique because of the delayed presentation and diagnosis of a large sub-capsular hematoma nearly 6 days after the index ERCP. The association with chronic pancreatitis and this complication bears special mention as it is seen in this case and 4 other reports as noted. We suggest that although the data are retrospective and associative in nature, chronic pancreatitis could be considered a risk factor for this rare but serious complication of ERCP. Recognition of this potentially life-threatening condition requires a high index of suspicion in order to achieve proper diagnosis and best management of the patient.

\section{Disclosure Statement}

No financial relationships with a commercial entity producing healthcare-related products and/or services relevant to this article exist with any of the authors listed. None of the authors has any conflicts of interest to disclose.

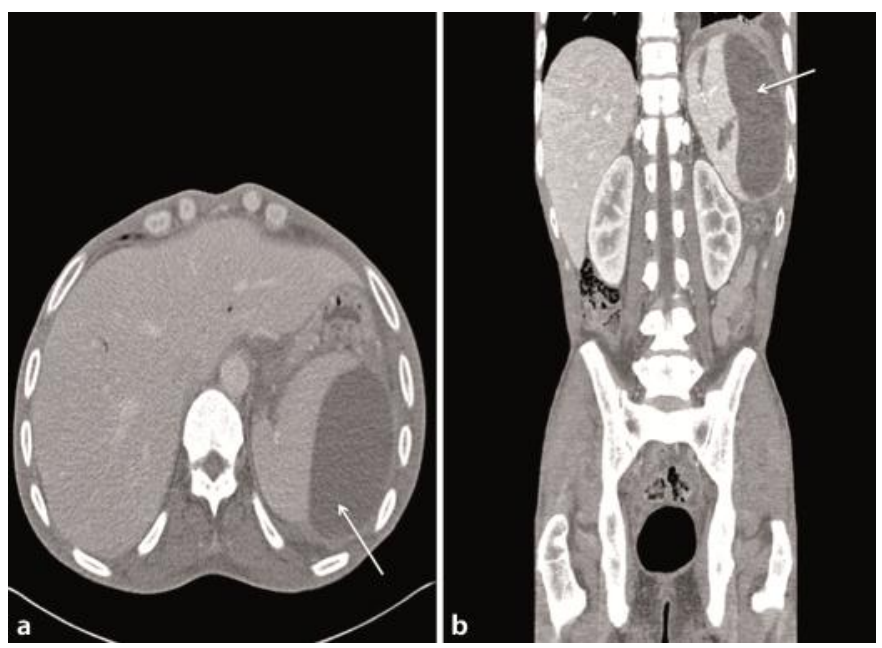

Fig. 1. Axial (a) and frontal (b) CT scan views revealing a large splenic laceration with associated sub-capsular fluid collection (arrows), measuring $9.7 \times 5.8 \mathrm{~cm}$ in axial dimension, without evidence of acute extravasation. 


\begin{tabular}{r|l|l|l}
$\begin{array}{r}\text { Case Reports in } \\
\text { Gastroenterology }\end{array}$ & $\begin{array}{l}\text { Case Rep Gastroenterol 2012;6:162-165 } \\
\text { DOI: 10.1159/000337499 }\end{array}$ & $\begin{array}{l}\text { Published online: } \\
\text { March 31, 2012 }\end{array}$ & $\begin{array}{l}\text { @ 2012 S. Karger AG, Basel } \\
\text { ISSN 1662-0631 } \\
\text { www.karger.com/crg }\end{array}$ \\
\hline
\end{tabular}

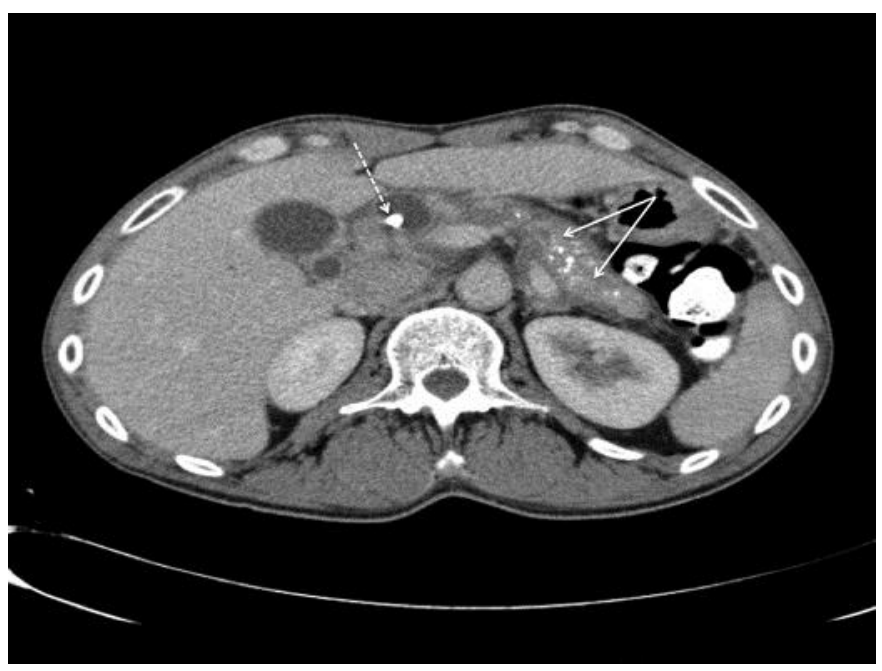

Fig. 2. Venous axial series CT scan demonstrating findings of chronic pancreatitis as evident by marked pancreatic calcifications (solid arrows) and a dilated common bile duct (dashed arrow) after stent placement during ERCP.

\section{References}

1 Aliperti G: Complications related to diagnostic and therapeutic endoscopic retrograde cholangiopancreatography. Gastrointest Endosc Clin N Am 1996;6:379-407.

-2 Pannu HK, Fishman EK: Complications of endoscopic retrograde cholangiopancreatography: spectrum of abnormalities demonstrated with CT. Radiographics 2001;21:1441-1453.

-3 Ahmed A, Eller PM, Schiffman FJ: Splenic rupture: an unusual complication of colonoscopy. Am J Gastroenterol 1997;92:1201-1204.

4 Trondsden E, Rosseland AR, Moer A, et al: Rupture of the spleen following endoscopic retrograde cholangiopancreatography (ERCP). Acta Chir Scand 1989;155:75-76.

5 Ong E, Bohmler U, Wurbs D: Splenic injury as a complication of endoscopy: two case reports and a literature review. Endoscopy 1991;23:302-304.

6 Lo AY, Washington M, Fischer MG: Splenic trauma following endoscopic retrograde cholangiopancreatography (ERCP). Surg Endosc 1994;8:692-693.

7 Lewis FW, Moloo N, Stiegmann GV, et al: Splenic injury complicating therapeutic upper gastrointestinal endoscopy and ERCP. Gastrointest Endosc 1991;37:632-633.

8 Wu WC, Katon RM: Injury to the liver and spleen after diagnostic ERCP. Gastrointest Endosc 1993;39: 824-827.

-9 Cho CL, Yuen KK, Yuen CH, et al: Splenic laceration after endoscopic retrograde cholangiopancreatography. Hong Kong Med J 2008;14:145-147.

10 Dixon E, Graham JS, Sutherland F, et al: Splenic injury following endoscopic retrograde cholangiopancreatography: a case report and review of the literature. JSLS 2004;8:275-277.

11 Kingsley DD, Schermer CR, Jamal MM: Rare complications of endoscopic retrograde cholangiopancreatography: two case reports. JSLS 2001;5:171-173.

12 Zyromski NJ, Camp CM: Splenic injury: a rare complication of endoscopic retrograde cholangiopancreatography. Am Surg 2004;70:737-739.

13 Furman G, Morgenstern L: Splenic injury and abscess complicating endoscopic retrograde cholangiopancreatography. Surg Endosc 1993;7:343-344.

14 Badaoui R, Ouendo M, Delcenserie R, et al: Injury to the liver and spleen after diagnostic ERCP. Can J Anaesth 2002;49:756-757.

15 Patil PV, Khalil A, Thaha MA: Splenic parenchymal complications in pancreatitis. JOP 2011;12:287-291. 